\title{
CLINICAL PROFILE OF OCULAR SURFACE SQUAMOUS NEOPLASIA: A RETROSPECTIVE CASE SERIES
}

\author{
Nibedita Acharya ${ }^{1}$, Raghavendra Ramappa², Reji Koshy Thomas ${ }^{3}$ \\ ${ }^{1}$ Associate Professor, Department of Ophthalmology, BGS Global Institute of Medical Sciences, Bangalore, Karnataka, India. \\ ${ }^{2}$ Senior Resident, Department of Ophthalmology, Mysore Medical College and Research Institute, Mysore, Karnataka, India. \\ 3Professor, Department of Ophthalmology, St. John's Medical College, Bangalore, Karnataka, India.
}

\section{ABSTRACT}

\section{AIM}

To describe clinical profile and outcome in patients with Ocular Surface Squamous Neoplasia (OSSN).

\section{METHODS}

Retrospective case series. The case records of 11 patients with OSSN over 3 years (2008-2011) with minimum follow up of 6 months were included in the study. Anterior segment findings were documented by slit lamp biomicroscopy. Details of the treatment (Mitomycin and surgery) given to these patients and histopathological report of the excision biopsy were documented.

\section{STATISTICAL METHODS}

Frequency counts with percentage are calculated for anterior segment findings, mode of treatment, Histopathology Examination (HPE) report and recurrence.

\section{RESULTS}

Out of 11 cases of OSSN, 7 cases (63.63\%) were males and 4 cases (36.36\%) were females. Mean age of patients was 40.45 (18-72) years. Four out of 11 patients (36.36\%) were HIV positive. Excision biopsy was done for 6 patients (54.54\%) and 5 patients (45.45\%) were treated with excision biopsy with local mitomycin C application. On histopathological examination 4/11 (36.36\%) had deeper tissue invasion (Invasive squamous cell carcinoma) and 7/11(63.63\%) had no invasion of deeper structures. Recurrence was seen in all 4 patients (36.36\%) with deeper tissue invasion, which was treated with repeat excision and topical mitomycin C application.

\section{CONCLUSION}

OSSN is commonly associated with HIV infection. So all suspected cases of OSSN should be screened for HIV infection. Mitomycin$\mathrm{C}$ is a good adjunct to surgical excision, both for primary and recurrent cases.

\section{KEYWORDS}

Asthma, Prevalence, Risk Factors.

HOW TO CITE THIS ARTICLE: Acharya N, Ramappa R, Thomas RK. Clinical profile of ocular surface squamous neoplasia: a retrospective case series. J. Evolution Med. Dent. Sci. 2016;5(21):1100-1103, DOI: 10.14260/jemds/2016/255

\section{INTRODUCTION}

Ocular Surface Squamous Neoplasia (OSSN) is an umbrella term coined by Lee and Hirst that encompasses dysplasia, carcinoma in situ, intraepithelial neoplasia and Squamous Cell Carcinoma (SCC) of the cornea and/or conjunctiva. ${ }^{1}$ It is the third most common ocular tumour after retinoblastoma and melanoma. ${ }^{2}$ The highest risk of OSSN was in older white men of Caucasian origin, particularly those living closer than 30degrees latitude from the equator. ${ }^{3}$ Incidence of OSSN has a wide geographical variation, ranging from 0.13 to 1.9 per 100,000 population. Males are affected more often than females. ${ }^{4}$ The average age of presentation is usually in the sixth and seventh decades. Advanced age, male gender, exposure to solar ultraviolet radiation, infection with Human Papilloma Virus (HPV), immunosuppression and infection with Human Immunodeficiency Virus (HIV) are the factors which play an essential role in the development of OSSN.

Financial or Other, Competing Interest: None.

Submission 17-02-2016, Peer Review 29-02-2016,

Acceptance 03-03-2016, Published 12-03-2016.

Corresponding Author:

Dr. Raghavendra Ramappa,

Senior Resident, Department of Ophthalmology,

Mysore Medical College and Research Institute,

Mysore, Karnataka, India.

E-mail: dr.raghuophthal@gmail.com

DOI: $10.14260 /$ jemds $/ 2016 / 255$
It presents more commonly in the interpalpebral area of perilimbal conjunctiva and can extend across the limbus to involve the cornea. OSSN can show isolated corneal involvement also; 79\% of HIV infected patients had OSSN in Africa. ${ }^{5}$ OSSN is often the first presenting feature of HIV infection in patients with no other medical problems. The tumours tend to occur at a younger age and behave more aggressively in this population. Patients with xeroderma pigmentosum also develop OSSN at a younger age. ${ }^{6}$ Early detection and treatment have role in decreasing the incidence of squamous cell carcinoma. Keeping this in mind, we retrospectively studied histopathologically proven cases of OSSN to evaluate the clinical profile and outcome of surgical procedure.

\section{MATERIAL AND METHODS}

This is a retrospective case series study done in Department of Ophthalmology, St. John's Medical College, Bangalore. The case records of 11 patients with OSSN over 3 years (2008-2011) with minimum follow up of 6 months were included in the study. The study was approved by the Ethical Committee of St. John's Medical College and adhered to the tenets of declaration of Helsinki. In each case a complete medical and surgical history was taken; ocular examination including location, extent and clinical appearance of the lesion was done. Anterior 
segment findings were documented by slit lamp biomicroscopy.

All the patients with the lesion were tested for HIV by Enzyme-Linked Immunosorbent Assay (ELISA). Details of the treatment (Mitomycin $\mathrm{C}$ and surgery) given to these patients and histopathological report of the excision biopsy were documented. The lesions were surgically excised keeping a safe margin of 2-3 mm of normal appearing conjunctiva. For the lesions extending into the cornea or the sclera, a superficial keratectomy or partial thickness sclerectomy was done. Cryotherapy was applied to the base and edges of the normal conjunctival margin to reach both superficial tumour islands and deeply infiltrated tumour cells. The cryo probe with 2.5 $\mathrm{mm}$ tip was inserted underneath the edges of resected conjunctiva to form an ice ball with rapid freeze with slow thaw, repeated two or three times [Freeze - thaw - refreeze].

The duration of cryotherapy was controlled depending on the location of lesion-the ice ball extending $2 \mathrm{~mm}$ for conjunctiva, $1 \mathrm{~mm}$ for episclera and $0.5 \mathrm{~mm}$ for the cornea. Limbal region was not spared. Cryo application was limited to 3 seconds to minimize the risk of Limbal stem cell damage. Excised tissue was sent for histopathological examination in all cases. Patients were put on Mitomycin C (MMC) $0.02 \%$ four times a day with one week on and one week off in alternating cycles for a maximum of 8 weeks. As MMC is relatively unstable in solution, it has to be refrigerated and a new bottle was dispensed for each week of treatment. Patients were followed up for at least 6 months. Frequency counts with percentage are calculated for anterior segment findings, mode of treatment, Histopathology Examination (HPE) report and recurrence.

\section{RESULTS}

The age of the patients at presentation varied from 18 years to 72 years with mean age of 40.45 years. Out of 11 patients, 7 were males (63.63\%) and 4 were females (36.36\%). Unilateral involvement was seen in 10 patients $(90.90 \%)$ and only one patient had bilateral involvement. In 6/11 (54.54\%) patients, tumour was located at the nasal side and in $5 / 11(45.4 \%)$ it was at temporal part of the ocular surface (Figure 1). Four out of 11 patients $(36.36 \%)$ were tested positive for HIV. One patient had associated Mycobacterium tuberculosis and 1 patient had xeroderma pigmentosum and was 18-year-old male. Excision biopsy was done for six patients (54.54\%) and five $(45.45 \%)$ were treated with excision biopsy with local mitomycin $\mathrm{C}$ application.

On histopathological examination, 4/11 (36.36\%) had deeper tissue invasion (Invasive Squamous Cell CarcinomaSCC) and 7/11 (63.63\%) had no invasion of deeper structuresFive patients had carcinoma in situ, one patient had irregular hyperplasia with dyskeratosis and others had full thickness dysplasia with foci of equivocal invasion (Table 1). On follow up, recurrence was seen in 4/11 (36.36\%) within 3-4 months of surgery, which was treated with repeat excision and local mitomycin C (MMC). All the 4 patients who had recurrences had deeper invasion on HPE report. Patients with Mycobacterium tuberculosis and xeroderma pigmentosum had deeper invasion and hence had recurrences after the surgery.

\begin{tabular}{|c|c|}
\hline $\begin{array}{l}\text { Number of } \\
\text { Patients }\end{array}$ & Histopathology Examination \\
\hline $5 / 11(45.45 \%)$ & $\begin{array}{l}\text { Carcinomas in situ (Conjunctival } \\
\text { intraepithelial neoplasia) }\end{array}$ \\
\hline $4 / 11(36.36 \%)$ & $\begin{array}{l}\text { Invasive squamous cell carcinoma } \\
\text { (SCC) }\end{array}$ \\
\hline $1 / 11(9.09 \%)$ & Irregular hyperplasia with dyskeratosis \\
\hline $1 / 11(9.09 \%)$ & $\begin{array}{c}\text { Full thickness dysplasia with foci of } \\
\text { equivocal invasion }\end{array}$ \\
\hline \multicolumn{2}{|c|}{$\begin{array}{l}\text { Table 1: Histopathology Examination } \\
\text { Results in the Study Patients }\end{array}$} \\
\hline
\end{tabular}

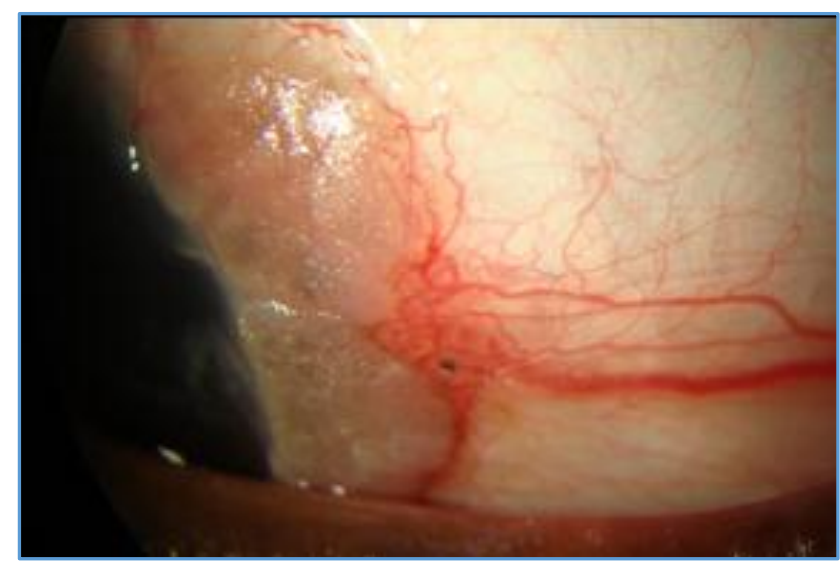

Fig. 1: A case OSSN in Temporal Part of the Conjunctiva in the Left Eye

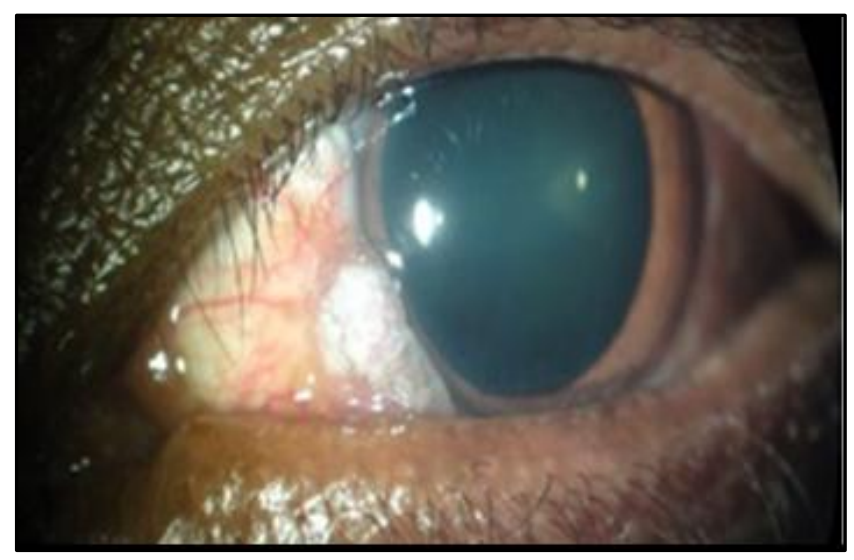

Fig. 2: OSSN in Left Eye of HIV Patient

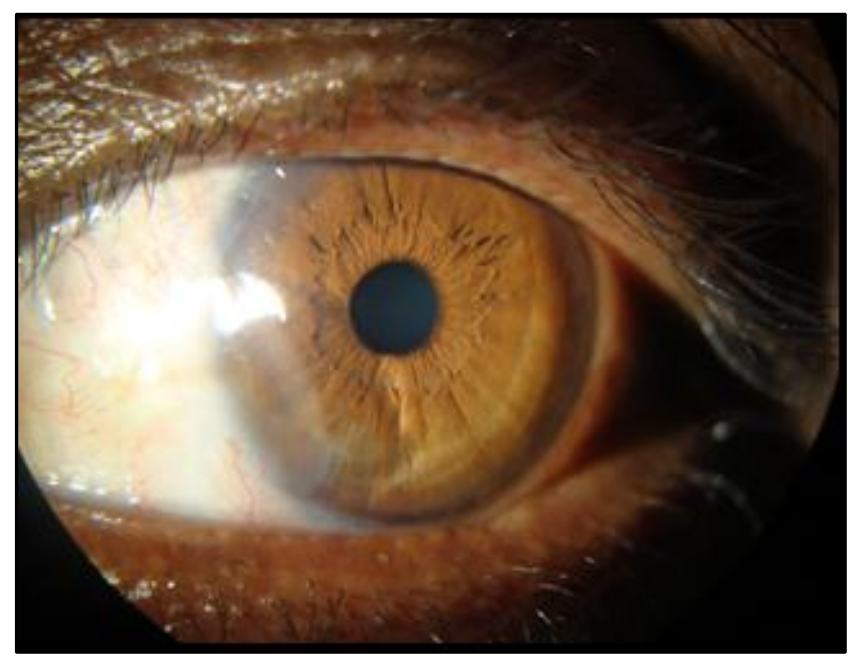

Fig. 3: Post Excision with Mitomycin C after 1 Month Followup 


\section{DISCUSSION}

In our study, on histopathological examination $36.36 \%$ had invasive SCC and $63.63 \%$ had no invasion of deeper structures. Andrew A. Kao et al. ${ }^{7}$ reviewed retrospective case series of 612 consecutive OSSN lesions to describe the clinical and histologic characteristics of ocular surface squamous neoplasia lesions. Over the studied period, $33 \%$ of submitted specimens were characterized as mild, moderate or severe dysplasia; $52 \%$ were classified as carcinoma in situ and $11 \%$ were graded as squamous cell carcinoma. Our study results are also similar.

But in another study conducted by Kavitha Toopalli, et al. ${ }^{8}$ biopsies from 168 patients with histologically proven OSSN were included. Histological spectrum showed welldifferentiated SCC 34 (33.3\%), moderately differentiated SCC 53 (51.9\%) and poorly differentiated SCC 15 (14.7\%) Recurrence was seen in 31 cases $(18.4 \%)$ at the limbus. Histological spectrum showed more of invasive $102(60 \%)$ than non-invasive $68(40 \%)$ lesions. Histopathological examination of the lesion is mandatory to decide the line of management and to prognosticate the case.

Primary excision has been the mainstay of treatment for OSSN. ${ }^{9}$ Superficial excision remains the important initial step in management, as it is impossible to exclude invasive disease on clinical grounds or with impression cytology. Excision allows an immediate histopathological diagnosis, surgical debulking and set aside life threatening invasive carcinoma. ${ }^{10}$ The disadvantage of primary excision alone is the high recurrence rate, which ranges from $15 \%$ to $52 \% .^{2}$ Therefore, numerous adjunctive treatments have been described in an attempt to decrease the rate of recurrence and the efficacy of various adjunctive therapy have been debated.

Cryotherapy is often used in conjunction with surgery. It acts by directly destroying the tumour cells by lowering the temperature and also by causing ischemic necrosis. Intraoperative cryotherapy is commonly used as adjunctive therapy, as it is known to decrease the recurrence rate by destruction of any residual tumour tissue beyond the horizontal or deep surgical margin of the wound. It has the advantage of reaching both tumour cell islands and deeply infiltrated cells, thus obviating the need for radical surgery. ${ }^{11}$

Mitomycin C (MMC) is an alkylating agent, which acts by inhibiting DNA synthesis and produces cell death by apoptosis and necrosis. ${ }^{12}$ The drug has a preferential action for rapidly dividing cells and has significant anti-tumour activity. Since 1994 several groups have reported the use of MMC in the treatment of both primary and recurrent OSSN.12-17 MMC allows treatment of the entire ocular surface including the conjunctival fornices and may reach and destroy subclinical disease and prevent new tumours arising elsewhere on the ocular surface. We think it is unwise to use only MMC without excision biopsy for localised OSSN, as invasive disease may be undiagnosed and MMC is unlikely to penetrate to the required level to reach the invasive cells.

In our study, $54.54 \%$ were treated with excision biopsy and $45.45 \%$ were treated with excision biopsy with local Mitomycin C (MMC) application. Recurrence was seen in $36.36 \%$, which was treated with repeat excision and mitomycin C. Recurrence rates for pre-invasive and invasive OSSN following surgical excision range from $15 \%$ to $52 \%{ }^{2}$

Pinnita Prabhasawat, et al. conducted a study to demonstrate the efficacy of topical $0.002 \%$ Mitomycin C (MMC) as an adjunctive and alternative treatment in primary and recurrent Conjunctival-Corneal Intraepithelial Neoplasia (CCIN) and Squamous Cell Carcinoma (SCC). The medical records of 7 patients with histopathologically confirmed CCIN and conjunctival SCC were retrospectively reviewed. All cases were treated with topical $0.002 \%$ MMC 4 times daily.

The tumour size pre- and post-treatment, clinical response and ocular complications were evaluated. Six patients had pathologically proven CCIN (85.7\%) and 1 had SCC (14.3\%). Before MMC treatment, 6 eyes (85.7\%) had recurrences after surgical excision. The tumour-free period ranged from 2 to 19 months. Two patients had multiple recurrences. MMC $0.002 \% 4$ times daily was applied for a period of 5.4+/-4.4 weeks (Range 2-14). All had complete tumour regression as observed clinically and confirmed by impression cytology. The mean follow up time was 30.7+/-15 months (Range 2-52) with no evidence of clinical recurrence in any case. Topical MMC not only effectively eradicates the tumour, but also reduces the recurrence rate from $29 \%$ after surgical excision to $14.3 \% .^{17}$

Khokhar S, et al. ${ }^{9}$ conducted a study to report the outcome of combined excision, cryotherapy and antimetabolite treatment of recurrent ocular surface squamous neoplasia. The patients with recurrent OSSN were treated by excision of lesion, cryotherapy of limbus and conjunctival margin followed by $0.02 \%$ Mitomycin C application at the time of surgery. Patients have been followed up for at least 1 year. They concluded that combining excision with cryotherapy and Mitomycin C application at the time of surgery is a very effective therapy for recurrent ocular surface squamous neoplasia. It is relevant for cases in large, poor countries where patients present late and are less likely to come for follow up care.

A Gupta, et al. ${ }^{16}$ concluded that MMC treatment following surgical excision appears to decrease the recurrence rate of localized CCIN and should be considered as adjuvant therapy in primary treatment.

In our study, 4/11 (36.36\%) were tested positive for HIV (Figure 2 and 3). Martin S Spitzer, et al. ${ }^{5}$ conducted a study to evaluate the prevalence of undiagnosed and asymptomatic HIV infection in patients with Ocular Surface Squamous Neoplasia (OSSN). They did a detailed history and physical examination in 53 consecutive patients with conjunctival squamous cell carcinoma and conjunctival intraepithelial neoplasia. Thirty-eight (72\%) patients agreed to undergo serological HIV testing. Seventy nine percent $(30 / 38)$ patients were HIV positive. None of the patients had previous HIV testing or was aware of having symptoms of HIV. Seventy percent of the HIV-positive patients had no other symptoms suggestive of HIV infection or any other disease. The conjunctival tumour may be the primary and only apparent manifestation of HIV in patients presenting with OSSN in SubSaharan Africa.

Porges, Yair, et al.18 did a study to evaluate the prevalence of HIV seropositivity among patients with malignant conjunctival Squamous Cell Carcinoma (SCC) and Carcinoma In Situ (CIS). Conjunctival malignancy was the first presenting sign for AIDS in $50 \%$ of their patients. They concluded that a significantly high rate of HIV seropositivity was found in a group of African black patients with conjunctival SCC/CIS compared with a control group with benign conjunctival lesions. Therefore, an HIV test should 
probably be performed in all cases of conjunctival SCC/CIS or dysplasia.

In our study population, one patient had associated Mycobacterium tuberculosis infection and one patient had xeroderma pigmentosum. Both the patients had deeper invasion and hence had recurrences after the surgery. Gupta $\mathrm{N}$, et al. ${ }^{6}$ in their study on the clinical spectrum and therapeutic outcome of Ocular Surface Squamous Neoplasia (OSSN) in patients with Xeroderma Pigmentosa (XP) concluded that OSSN occurs predominantly in the elderly, but in patients of XP it tends to occur at a younger age. The disease appeared to be more aggressive than usual. Awareness and prompt management with close follow up is warranted in these patients. Our patient of XP was 18 years old.

\section{CONCLUSION}

OSSN is commonly associated with HIV infection. So all suspected cases of OSSN should be screened for HIV infection. Superficial excision remains the important initial step in management, as it is impossible to exclude invasive disease on clinical grounds or with impression cytology. Excision allows an immediate histopathological diagnosis, surgical debulking and excludes life threatening invasive carcinoma. Mitomycin$\mathrm{C}$ is a good adjunct to surgical excision, both for primary and recurrent cases.

\section{REFERENCES}

1. Christine A Kiire, Sathish Srinivasan, Carol L Karp. Ocular surface squamous neoplasia. International ophthalmology clinics summer 2010;50(3):35-46.

2. Lee GA, Hirst LW. Ocular surface squamous neoplasia. Surv Ophthalmol 1995;39:429-450.

3. Basti S, Macsai MS. Ocular surface squamous neoplasia: a review. Cornea 2003;22:687-704.

4. Ash JE. Epibulbar tumours. Am J Ophthalmol 1950;33:1203.

5. Spitzer MS, Batumba NH, Chirambo T, et al. Ocular surface squamous neoplasia as the first apparent manifestation of HIV infection in Malawi. Clin Experimen Ophthalmol 2008;36:422-425.

6. Gupta N, Sachdev R, Tandon R. Ocular surface squamous neoplasia in xeroderma pigmentosum: clinical spectrum and outcome. Graefes Arch Clin Exp Ophthalmol 2011;249(8):1217-21.
7. Andrew A Kao, Anat Galor, Carol L Karp, et al. Clinicopathologic correlation of ocular surface squamous neoplasms at Bascom palmer eye institute: 2001 to 2010. Ophthalmology 2012;119(9):1773-1776.

8. Kavitha Toopalli, Vivekanand Namala, Modini Pandharpukar, et al. Ocular surface squamous neoplasia impression cytology V/S histopathology. Sch J App Med Sci 2014;2(1D):461-465.

9. Khokhar S, Soni A, Singh Sethi H, et al. Combined surgery, cryotherapy and mitomycin-C for recurrent ocular surface squamous neoplasia. Cornea 2002;21:189-91.

10. Kaines A, Davis G, Selva D, et al. Conjunctival squamous cell carcinoma with perineural invasion resulting in death. Ophthalmic Surg Lasers Imaging 2005;36:249251.

11. Sudesh S, Rapuano CJ, Cohen EJ, et al. Surgical management of ocular surface squamous neoplasms: the experience from a cornea center. Cornea 2000;19:27883.

12. McKelvie PA, Daniell M. Impression cytology following mitomycin $\mathrm{C}$ therapy for ocular surface squamous neoplasia. Br J Ophthalmol 2001;85:1115-19.

13. Frucht-Pery J, Sugar J, Baum J, et al. Mitomycin C treatment for conjunctival-corneal intraepithelial neoplasia-a multicenter experience. Ophthalmology 1997;104:2085-93.

14. Kemp EG, Harnett AN, Chatterjee S. Preoperative topical and intraoperative local mitomycin $\mathrm{C}$ adjuvant therapy in the management of ocular surface neoplasias. $\mathrm{Br} \mathrm{J}$ Ophthalmol 2002;86:31-4.

15. Shields CL, Naseripour M, Shields JA. Topical mitomycin C for extensive, recurrent conjunctival-corneal squamous cell carcinoma. Am J Ophthalmol 2002;133:601-6.

16. Gupta A, Muecke J. Treatment of ocular surface squamous neoplasia with mitomycin $\mathrm{C}$. Br J Ophthalmol 2010;94(5):555-558.

17. Pinnita Prabhasawat, Patamanuch Tarinvorakup, Nattaporn Tesavibul, et al. Topical $0.002 \%$ mitomycin C for the treatment of conjunctival-corneal intraepithelial neoplasia and squamous cell carcinoma. Cornea 2005;24:443-448.

18. Porges Yair, Groisman Gabriel M. Prevalence of HIV with conjunctival squamous cell neoplasia in an African provincial hospital. Cornea 2003;22(1):1-4. 